\title{
Grease-gun Injury
}

\author{
MICHAEL G. H. SMITH,* M.B., F.R.C.S.ED
}

Brit. med. Э., 1964, 2, 918-920

The purpose of this paper is to alert clinicians in hospital and general practice to the importance of an injury caused by the misuse of high-pressure lubrication equipment in the garage trade. The paucity of reports in the English literature does not do justice to the frequency and importance of this injury.

My attention was drawn to this subject by the occurrence in 1963 of three grease-gun injuries whose treatment I undertook. In the course of investigating the circumstances of chassis lubrication two similar injuries which had occurred some years before were brought to light. The methods of lubrication causing these injuries and the five cases of greasegun injury are described.

In modern apparatus the pressure of grease at the nozzle is usually in the region of 5,000-10,000 lb./sq. in. (351.5-703 kg./ sq. cm.). This pressure is obtained by using a compressed-air supply of up to $150 \mathrm{lb} . / \mathrm{sq}$. in. $(10.5 \mathrm{~kg} . / \mathrm{sq}$. cm.) to drive a pump which steps up the pressure by as much as 70 times.

The nipples commonly used on car chassis are either the zerk (now obsolete) or the hydraulic type (Fig. 1). To force grease into the bearings two types of gun nozzle are available -the zerk, which essentially consists of a hollow probe that enters the hole in the face of either type of nipple (Fig. 2), and the hydraulic type, which sits over the bulbous tip of the hydraulic nipple and is clasped to it by three spring-loaded claws (Fig. 3). The critical feature of these nozzles is the size of hole through which grease is delivered at high pressure. The hydraulic nozzle possesses a relatively large hole from which grease is extruded in a broad slow stream, while from the small orifice of the zerk nozzle grease is expelled in a jet at high velocity (Fig. 3). It was this high-speed jet from the zerk nozzle which caused the injury in four of the five patients seen at the Western Infirmary, Glasgow. In addition, the unguarded zerk nozzle can easily slip off a nipple and by its pointed shape cause injury. All nozzles can be fired free, although manufacturers have recently begun production of a type of nozzle which will allow exit of grease only when it is thrust on to the nipple.

In order to estimate the degree of awareness of the dangers of grease-guns, visits were made at random to 35 garages in Glasgow. In 16 of these the personnel were unaware of the possibility of injury. In more than half of the garages zerk nozzles were in use and few mechanics appreciated the difference in safety of the two types of nozzle.

The condition is insufficiently known to doctors, as is shown by the fact that the special nature of three grease-gun injuries in 1963 was not appreciated by the casualty officers called to deal with them.

\section{Case Reports}

Case 1.-In 1951 a 41-year-old mechanic, who was unaware of the danger, was testing an unguarded zerk-nozzled grease-gun when he accidentally directed the jet at his left middle finger. The grease entered the palmar aspect of the middle segment from a distance of several inches. At the casualty department he was treated for two weeks with poultices and a variety of dressings, during which time grease and slough discharged. Gangrene developed, necessitating an amputation through the proximal phalanx of the finger on the fifteenth day. Healing of the stump was slow.

* Orthopaedic Senior Registrar, Western Infirmary, Glasgow.
Case 2.-In 1956 a 65-year-old mechanic using a hydraulicnozzled grease-gun injected grease into his left palm at the base of the middle finger. Some grease was expressed from the wound at the time of injury and again two days later by his own doctor, who treated him with penicillin and dressings for a supposed hand

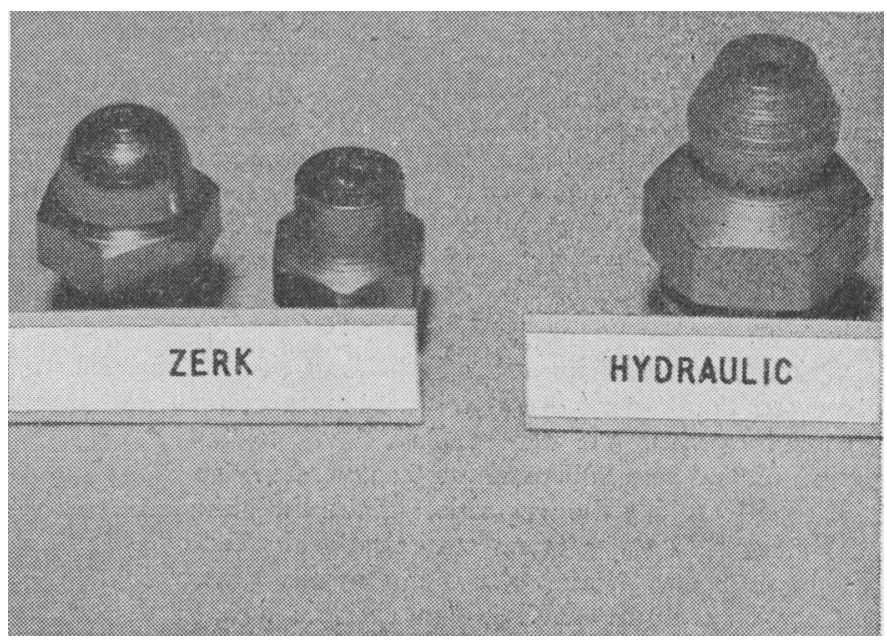

FIG. 1.-Nipples of zerk type, now obsolete, and the bulbous tipped hydraulic nipple now in general use on cars.

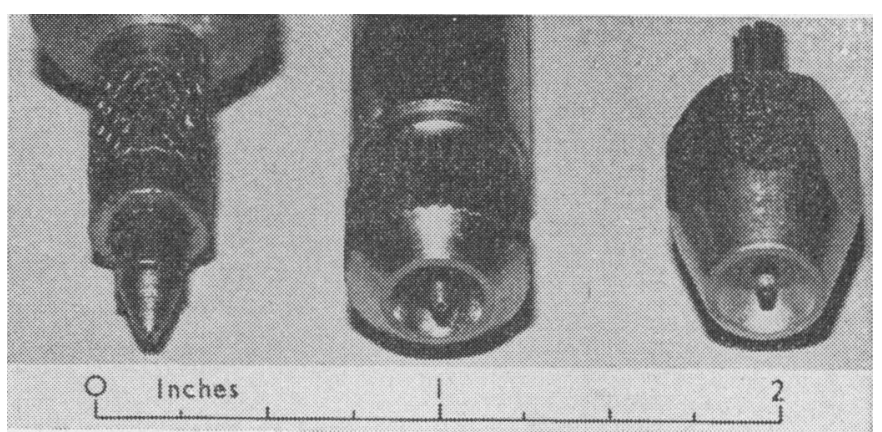

FIG. 2.-Three grease-gun nozzles of the zerk type showing the fine probe which enters the hole on the face of the nipple. The nozzle on the left is of the unguarded variety. (Scale in inches.)

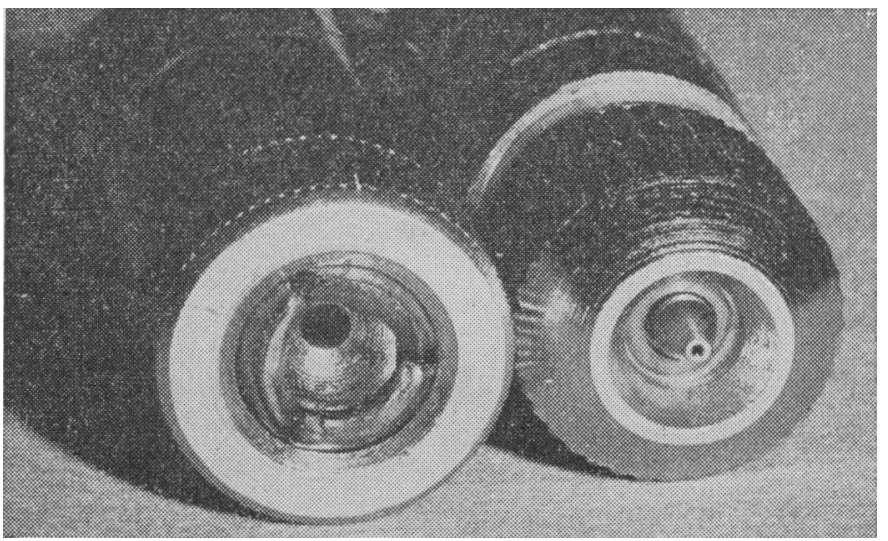

FIG. 3. - Comparison of the size of hole through which grease is delivered in the hydraulic nozzle (left) and a guarded zerk nozzle (right). The difference in cross-section is about 30 times. 
infection. On the sixth day, as inflammation became widespread, he was referred to the casualty department, where the palmar wound was opened under local anaesthetic and packed with gauze, and streptomycin was given for a few days. On the tenth day a large fluctuant abscess which had formed on the dorsum of the hand was incised. The pus removed was sterile. The wounds did not heal for several weeks, and after 10 weeks he still had stiffness in his fingers and hand.

Case 3.-In March 1963 a 33-year-old garage service manager, who was unaware of the danger, held out his hand to receive a small quantity of grease. An unguarded zerk-nozzled grease-gun was fired from several inches away and the jet of grease entered the palmar surface of the right ring-finger at the proximal interphalangeal joint. There was little or no pain at the time, and when he attended the casualty department shortly after the injury its significance was not appreciated. He was treated with a simple dressing, penicillin, and tetanus toxoid. The case was discovered at review, and the patient was recalled 48 hours after the injury, by which time the pain in the finger was severe. A wide exploration of the finger was carried out and large quantities of grease were removed. Healing of the finger was delayed for several weeks owing to necrosis of the skin flaps, but ultimately the function of the finger was normal.

Case 4.-In June 1963 a 37-year-old mechanic, who was aware of the dangers, was using a guarded zerk-nozzled grease-gun when it slipped off an inaccessible nipple. The jet of grease entered the proximal segment of the right index finger from a distance of several inches. Some grease was expressed at the time. There was little pain, and when he attended the casualty department shortly afterwards the significance of the injury was not appreciated. The finger was dressed and he was discharged. Later severe pain developed and he returned to hospital 24 hours after the injury. There was now much inflammation in the finger and sensation was impaired. The finger was widely explored and grease and oedematous fat were excised. Healing occurred without delay. Some weeks later painless swellings developed on the finger, which discharged sterile pus on several occasions. Three months after the injury an implantation dermoid and much fibrous tissue were excised from the finger, and function became almost normal.

Case 5.-In August 1963 a 54-year-old mechanic, who was aware of the dangers of grease-gun injury, accidentally fired the grease-gun while cleaning it. He had been pumping paraffin through the unguarded zerk nozzle to clear it of a blockage, and the jet of fluid which entered the palmar aspect of the base of the left middle finger consisted mainly of paraffin and a little grease. Pain was immediate and severe. He attended the casualty department, where the significance of the injury was not appreciated. After a limited exploration of the entrance wound under local anaesthesia his hand was dressed and he was sent home. Increasing pain forced him to return to hospital a few hours later, by which time the dorsum of his hand was very swollen and the middle finger was swollen and insensitive. The finger and palm were explored and some grease was removed. On opening the dorsum of the hand copious fluid smelling strongly of paraffin was squeezed out and the wounds were closed. During succeeding days there was much pain, marked lymphangitis of the arm, and gangrene of the middle and ring fingers seemed imminent. On the sixth day a large collection of sterile pus was released from the dorsum of the hand. On the thirteenth day the middle and ring fingers were gangrenous and amputation was performed through the necks of the corresponding metacarpals. Areas of skin-loss required grafting, and, although the thumb and smallest finger work well, the index finger is stiff and the function of the hand is severely impaired. (Cases 3,4 , and 5 were treated by me.)

\section{Discussion}

Including the five patients described above there have been 31 cases of high-pressure oil-injection injury recorded in the English literature (Rees, 1937 ; Dial, 1938 ; Brooke and Rooke, 1939 ; Smith, 1939 ; Hughes, 1941 ; Mason and Queen, 1941 ; Byrne, 1944 ; Bell, 1952 ; Tempest, 1953 ; Vivian and Christian, 1956 ; Rains, 1958 ; Harrison, 1959 ; Innes, 1959 ; Yaxley, 1960 ; Stark et al., 1961 ; Bottoms, 1962). In addition brief mention of the condition has been made in specialized textbooks of hand surgery (Bunnell, 1956 ; Rank and Wakefield, 1960 ; Clarkson and Pelly, 1962 ; Bailey, 1963). Of these, 22 have involved the injection of grease, five diesel oil, and the rest a variety of other oils.

The special nature of grease-gun injury depends upon two main factors-physical distension and chemical irritation. Physical distension occurs immediately at the time of injection, and as the part fills out to the limit of its elasticity the pressure developed in the tissues causes embarrassment of the circulation. In addition the pressure on nerves may cause numbness, and the condition is often painless for a day, leading to delay in seeking advice. Chemical irritation of the grease first causes acute inflammation and later a marked foreign-body reaction develops. Massive fibrosis, encysted collections of oil, and sinus formation may be found at a late stage and account for much loss of function.

The sequence of the pathological process can be shown diagrammatically as follows:

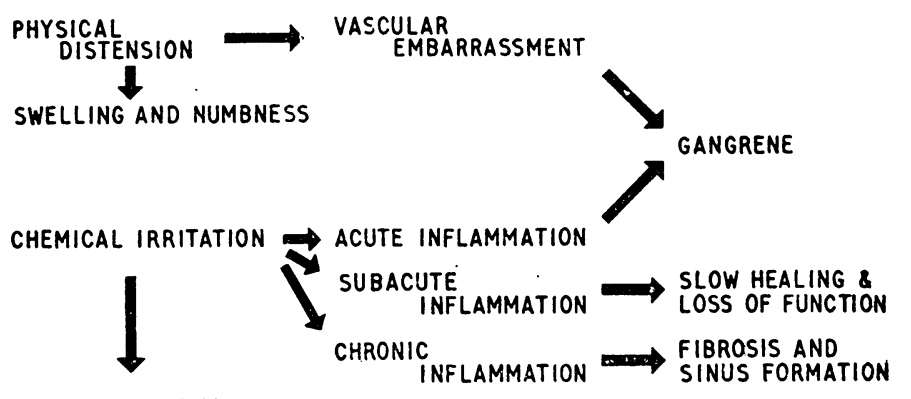

PAIN AND NUMBNESS

It is doubtful if infection is important, as there is no convincing evidence of this in earlier reports, and in three cases described in this paper pus was sterile.

The logical treatment is to carry out early exploration of the part to secure reduction of physical distension and removal of the chemical irritant by exćision of grease and contaminated non-essential tissue. Chemical solvents of grease should not be used as they are themselves irritant.

That such exploration should be carried out early is supported by the earlier reports. In only 7 out of 22 cases of grease injury was a good result obtained, and these seven had had wide exploration. In the remainder, treated more conservatively, the results were poor, often involving amputation.

When diesel and other light oils were involved the chemical irritation was so acute that gangrene developed quickly and even early surgery failed to save the part.

\section{Summary and Conclusions}

The circumstances under which high-pressure chassis lubrication in garages is carried out are described. The main factor in the causation of injury by grease-gun is the type of nozzle chosen for use. The jet of grease fired from a nozzle possessing a fine orifice is capable of penetrating the tissues from some distance, giving rise to serious injury in the hand, the treatment of which is a matter of urgency and difficulty. Five cases of grease-gun injury, including their treatment and the end-results, are described. An estimate of the lack of awareness of the dangers of such injury has been made in garages in Glasgow.

There is a lack of awareness among doctors of the serious nature of grease-gun injuries and a lack of awareness of the dangers of high-pressure lubrication equipment among garage workers.

Grease-gun injuries should be treated as emergencies; a wide exploration of the part is essential to remove as much grease as possible.

I wish to thank Professor Roland Barnes and Mr. A. R. Parkes for their encouragement and helpful criticism in the preparation of this paper. I also wish to thank the officials of Castrol Ltd., Kismet 
Ltd., Laycock Engineering Ltd., Stewart-Warner Ltd., and in particular Mr. M. G. Connell and Mr. B. C. Curren, of Tecalemit (Engineering) Ltd., for technical information supplied.

\section{REFERENCES}

Bailey, D. A. (1963). The Infected Hand, p. 139. Lewis, London. Bell, R. C. (1952). Brit. F. plast. Surg., 5, 138.

Bottoms, R. W. A. (1962). Med. f. Aust., 2, 591.

Brooke, R., and Rooke, C. J. (1939). Brit. med. f., 2, 1186

Bunnell, S. (1956). Surgery of the Hand, 3rd ed., p. 725. Pitman Medical Publishing Co., London.

Byrne, J. J. (1944). F. Amer. med. Ass., 125, 405.

Clarkson, P., and Pelly, A. (1962). The General and Plastic Surgery of the Hand, p. 390. Blackwell, Oxford.
Dial, D. E. (1938). F. Amer. med. Ass., 110, 1747.

Hughes, J. E. (1941). f. Amer. med. Ass., 116, 2848.

Innes, C. B. (1959). N.Z. med. F., 58, 177.

Mason, M. L., and Queen, F. B. (1941). Quart. Bull. Northw. Univ. mea. Sch., 15, 122 .

Rains, A. J. H. (1958). Brit. med. F., 1, 625.

Rank, B. K., and Wakefield, A. R. (1960). Surgery of Repair as Applied to Hand Iniuries, 2nd ed., p. 141. Livingstone, Edinburgh and London.

Rees C. E. (1937). 7. Amer. med. Ass., 109, 866.

Smith, F. H. (1939). Ibid., 112, 907 .

Stark, H. H., Wilson, J. N., and Boyes, J. H. (1961), F. Bone ft Surg., 43A, 485 .

Tempest, M. M. (1953). Univ. Leeds med. F., 2, 125.

Vivian, D. N., and Christian, S. G. (1956). Industr. Med. Surg., 25, 282.

Yaxley, R. P. (1960). Brit. med. F., 2, 714.

\section{Preliminary Communications}

\section{Liver Function after Long-term Progesta- tional Treatment with and without Oestrogen}

\section{Brit. med. F., 1964, 2, 920-921}

Several reports have appeared indicating that a number of therapeutically valuable steroids may alter the excretory function of the liver, as judged by the results of the so-called liverfunction tests and the (sporadic) occurrence of jaundice. The presence of an alkylated group at $\mathrm{C} 17$ has been incriminated with regard to the hepatic effects observed with compounds such as methyltestosterone, notethandrolone (17 $\alpha$-ethyl-19nortestosterone), methyloestrenolone (17 $\alpha$-methyl-19-nortestosterone), and methandienone ( $\Delta^{1}-17 \alpha$-methyltestosterone) (Sherlock, 1962). The particular importance of checking the possible hepatotoxicity of any steroidal product intended for long-term use as an oral contraceptive has been emphasized (Lancet, 1962). In this connexion some data have been reported for norethynodrel (17 $\alpha$-ethynyl-5(10)-oestrenolone) (Marquardt et al., 1961), norethisterone (norethindrone ; 17 $\alpha$-ethynyl-19-nortestosterone) (Drill, 1959 ; Rice-Wray et al., 1962), and norethisterone acetate (Perez-Mera and Shields, 1962), which suggests that these steroids, all of which have proved useful for contraception, may similarly affect hepatic function, though this, at least for norethynodrel, has recently been denied by a group of investigators with very wide experience in the matter (Garcia and Pincus, 1964).

In the past three years we have acquired much experience with the progestational and ovulation-inhibiting steroid $17 \beta-$ hydroxy-17 $\alpha$-ethynyloestr-4-en (lynoestrenol ; Orgametril) and its combination with the oestrogen mestranol (as Lyndiol). Orgametril ( $5 \mathrm{mg}$. tablets) and the combined products, Lyndiol (tablets with $5 \mathrm{mg}$. lynoestrenol and $150 \mu \mathrm{g}$. mestranol) and Lyndiol 2.5 (tablets with $2.5 \mathrm{mg}$. lynoestrenol and $75 \mu \mathrm{g}$. mestranol), have been successfully given to over 300 women either for the management of various gynaecological disorders or for contraceptive purposes (Linthorst, to be published). Although we have in no instance observed jaundice or other signs of hepatic involvement, we decided to ascertain, by means of adequate blood tests, whether any disturbance of liver function occurred in long-term treatment with these products.

\section{Material AND Methods}

Liver-function tests have been performed once in 52 women aged 18 to 48 who had been receiving Orgametril ( 26 women), Lyndiol (23 women), or Lyndiol 2.5 (3 women) for periods of
14 to 43 months, and who were still taking the tablets when the tests were carried out. Orgametril was administered at a daily dose of $5 \mathrm{mg}$., without interruption, whereas Lyndiol or Lyndiol 2.5 was usually given cyclically in daily doses of one tablet for 20 days (days 5 to 24 of the cycle) in order to restore or mimic menstrual periodicity. Indications for starting the treatment with any of the three products included menorrhagia, endometriosis, and dysmenorrhoea in a total of 38 women; the remaining 14 women received either Orgametril ( 2 women) or Lyndiol (12 women) primarily for contraception.

The blood examinations performed were the following (upper limits of the values considered normal in the laboratories concerned are given in parentheses): total serum bilirubin (1 mg./ $100 \mathrm{ml}$.) ; serum alkaline phosphatase (2.3 Bessey-Lowry units or 6 Bodansky units) ; thymol turbidity test (2.5 units); serum glutamic oxalo-acetic transaminase (S.G.O.T.) (40 units); serum glutamic pyruvic transaminase (S.G.P.T.) (35 units). Serum alkaline phosphatase and thymol turbidity tests were performed in all the women, the other tests in all but 12 women (six receiving Orgametril and six Lyndiol).

\section{RESUT.TS}

Except in two questionable cases; specified below, the results of the liver-function tests did not reveal any value outside the normal limits. The values obtained for bilirubin ranged between 0.30 and $0.91 \mathrm{mg}$.; for alkaline phosphatase between 0.8 and 2.2 Bessey-Lowry units or between 1.4 and 4.2 Bodansky units; for thymol turbidity test between 0.2 and 2.2 units; for S.G.O.T. between 5 and 21 units; and for S.G.P.T. between 4 and 31 units. In one woman aged 42 , who had been treated with Orgametril for 31 months because of endometriosis, an isolated value of 2.4 Bessey-Lowry units for alkaline phosphatase was found; in this woman bilirubin was $0.64 \mathrm{mg}$., thymol turbidity test 1.3 units, S.G.O.T. 10 units, and S.G.P.T. 7 units. In another woman, 30 years old, who had taken Lyndiol 2.5 during 18 months for menorrhagia, the thymol turbidity test was 2.6 units; in this case also the other values were normal (bilirubin $0.72 \mathrm{mg}$., alkaline phosphatase 1.4 Bessey-Lowry units, S.G.O.T. 5 units, and S.G.P.T. 10 units).

Pretreatment control values were not available, but these, in view of the results obtained, would have proved unnecessary. As mentioned above, none of the women reported or showed any clinical sign of liver disease during treatment with Orgametril, Lyndiol, and Lyndiol 2.5.

\section{Discussion}

The described results of the liver-function tests (a total of 224 determinations) are obviously reassuring. These data are 